\title{
THE LIPIDS OF SERUM AND LIVER IN PATIENTS WITH HEPATIC DISEASES ${ }^{1}$
}

\author{
By EVELYN B. MAN, BERNARD L. KARTIN, STANLEY H. DURLACHER AND \\ JOHN P. PETERS \\ (From the Departments of Internal Medicine, Psychiatry and Pathology of the Yale University \\ School of Medicine and the Medical Service of the New Haven Hospital, New Haven)
}

(Received for publication December 27, 1944)

The investigations of dietary fatty livers have thrown into prominent relief the function of the liver in the intermediary metabolism of lipids. The discovery that these disorders may be remedied or prevented by lipotropic agents may have important therapeutic implications since there is some evidence that the chemical and anatomical disturbances of the liver produced by some diseases and poisons resemble those found in dietary livers and that they may be amenable to the action of these lipotropic agents ( 1 to 3 ). These were among the reasons that led to an examination of the serum lipids in patients with diseases of the liver and pancreas and obstruction of the biliary system. . Such studies have been made before but have usually been confined to the determination of cholesterol, with or without fractionation, often by methods of doubtful accuracy. Because the interplay of the various lipid components appears to have significance apart from the concentration of any single constituent, as often as possible the lipids were fractionated into their 4 major components : fatty acids, lipid phosphorus, total cholesterol, and free cholesterol. From the values thus obtained, the cholesterol esters and neutral fat were estimated (4). In addition, samples of livers, secured at autopsy from some of the patients who had been studied, were analyzed for the same compounds. Finally, the effects of lipotropic agents on the course of the disease in certain of the patients are mentioned.

\section{EXPERIMENTAL}

Clinical material. Altogether 174 determinations of serum lipids were made on 70 patients. On some occasions, especially in the earlier studies, the lipids were not completely fractionated. The numbers of analyses for the various lipid frac-

1 Aided by a grant from the Fluid Research Fund of the Yale School of Medicine. tions, therefore, vary and complete comparisons cannot be made in all instances. All fractions were, however, measured in 125 observations on 54 of the cases. Proteins and protein fractions also were determined on 146 occasions.

The cases can be roughly classified under the following headings :

\begin{tabular}{|c|c|}
\hline Diagnosis & Number of cases \\
\hline $\begin{array}{l}\text { Obstruction of the common bile duct } \\
\text { Infectious hepatitis } \\
\text { Toxic hepatitis } \\
\text { Certain } \\
\text { Questionable }\end{array}$ & $\begin{array}{r}15 \\
11 \\
6\end{array}$ \\
\hline $\begin{array}{c}\text { Portal cirrhosis } \\
\text { Typical } \\
\text { Atypical }\end{array}$ & $\begin{array}{l}16 \\
12\end{array}$ \\
\hline $\begin{array}{c}\text { Biliary cirrhosis } \\
\text { Typical } \\
\text { Atypical }\end{array}$ & $\begin{array}{l}6 \\
2\end{array}$ \\
\hline Acute hemorrhagic pancreatitis & 2 \\
\hline
\end{tabular}

Some of these categories require explanation. Obstruction of the common bile duct includes patients with common duct stones, carcinoma of the pancreas, and other tumors which occluded the duct. In most instances, the diagnosis was confirmed by operation or post mortem examination. In all, there was evidence of acholia at some time. Studies were made before and after relief of obstruction in many cases; in a few only after operation; in others, who had inoperable conditions, at intervals during their illness.

The group termed infectious hepatitis is somewhat heterogeneous. All had febrile illnesses associated with icterus, usually accompanied by enlargement and tenderness of the liver. No evidence of exposure to hepatic poisons could be elicited from any of them. One had an antecedent history suggesting cholelithiasis of the gall-bladder, and $x$-rays at that time had revealed imperfect filling of the gall-bladder. In 4 instances, the liver remained somewhat enlarged after the acute attacks had subsided. In 1 of 
them, slight enlargement of the liver had been noted earlier. It may be argued that these subjects had cirrhosis or, since there was evidence of initial acholia, that they had painless transitory obstruction of the common bile duct with stones. Since they were not explored, the latter possibility cannot be denied. The course of their illnesses and of the icterus, however, was not that usually seen with common duct obstruction but was characteristic of hepatitis. All but 2 of the cases can be divided into 2 groups: (1) to which those just mentioned belong, in which icterus was an early and striking symptom, with evidence of initial acholia and variable febrile reaction; (2) cases in which icterus was a less prominent or relatively late phenomenon, while signs of hepatic insufficiency dominated the picture. All the fatalities occurred in this last group; but the distinction between the 2 types was not altogether one of severity, because 1 case belonging to the second group recovered. One of the 2 exceptional cases developed jaundice and signs of hepatic failure after a criminal abortion. E. coli was cultured from the blood of this patient. Another developed jaundice and a fatal acute nephritis after delivery. Both these patients died. They probably do not belong in the same category as the other patients with infectious hepatitis.

The diagnosis of toxic hepatitis also requires explanation. In 2, the hepatitis could be definitely attributed to an organic halide compound. In another, it arose from arsenical treatment of syphilis. A similar origin was suspected in a fourth. The fifth ran an extremely rapid fatal course resembling that of a toxic hepatitis. The only drug to which she is known to have been exposed is veronal, but it was impossible to secure an adequate history. An infectious etiology cannot be excluded.

The term portal cirrhosis signifies nothing but scarring of the liver that assumes a particular topographical distribution. Its causes are unknown. It has no more real standing as a disease than did the old renal scrapbasket, chronic interstitial nephritis, which has been abandoned. It may be produced by infectious or toxic agents and it may arise from dietary or nutritional deficiencies. The differentiation of typical from atypical cirrhosis, therefore, is somewhat specious. For this discussion, however, it may serve a use- ful purpose. The term typical is applied here to cases in which icterus was a comparatively insignificant, usually late, manifestation; in which the onset and development of the disease was insidious; and in which hepatomegaly, splenomegaly and ascites were prominent relatively early. The diagnosis was established at autopsy in 6 of the 16 cases. Of the atypical cases, 3 had histories of early jaundice with acholic stools. One of these and 2 additional patients had been subjected to cholecystectomy. Two of the patients had histories of intermittent or chronic diarrhea for long periods. In 1, x-ray revealed a gastric defect suggesting carcinoma. Two had chronic heart failure, 1 associated with cystic bronchiectasis. One had adhesive calcific pericarditis for which she was subjected to 2 unsuccessful operations. In the last, fibrosis of the pancreas and dilation of the pancreatic ducts were discovered at autopsy.

The diagnosis of typical biliary cirrhosis was established by autopsy 3 times. The other 3 patients had suffered from recurrent obstructive jaundice for periods of years. In every instance studies were made in the terminal stages of the disease. Protocols of 2 of these patients, 44700 and B43742, are presented below.

Of the 2 cases of acute hemorrhagic pancreatitis, 1 had a fulminating fatal course. The other was ill for 3 weeks. Autopsy revealed, in addition to fat necroses and other evidences of the pancreatic disease, a fistula to the gall-bladder, purulent bronchitis, and necrotizing cystitis and pyelitis.

Abstracts of the protocols of selected cases, including those from which liver specimens were taken, are given at the end of the paper.

\section{ANALYTICAL METHODS}

Blood was drawn when patients were in the postabsorptive state. Serum, separated with anaerobic precautions, was analyzed for lipids by methods previously described (4). Total protein, albumin, and globulin were also measured in most sera. Fractions were precipitated according to Howe and nitrogen was determined by macro Kjeldahl procedure. Van den Bergh tests, cephalin flocculation, prothrombin time, and bromsulfalein tests were done in many instances, icterus indices quite frequently.

Liver samples, after they had been weighed on an analytical balance and minced under alcohol and ether, were subjected to similar treatment. Attempts were made to secure samples from the most representative portions of the liver, usually the middle of the right lobe. Specimens 
for microscopic analysis were taken from the same region. The middle of the right lobe was chosen because it is usually possible in this region to find larger homogeneous areas of liver parenchyma. Although it has been suggested that there are inherent differences in the composition of the 2 lobes, depending upon the sources from which they derive their blood supply (5), the right lobe comprises the great mass of the liver.

Calculations. Concentrations of neutral fat were estimated by factors employed in previous studies (4). This involves the assumption that the proportions of the various phospholipids are the same in disease as they are in health, a hazardous, but inescapable assumption. When lipid phosphorus is high, any departure from these proportions will have a significant effect on the estimated value for neutral fat. In normal subjects and in many diseases the fatty acid combined with cholesterol can be estimated with accuracy from total cholesterol alone because the proportion of esters is so constant. In liver disease, this proportion is disturbed with great frequency. Unless the fractions are measured separately, therefore, estimations of fatty acids combined with cholesterol, and consequently of neutral fat, are unreliable. This also becomes an important source of error when total cholesterol is high. For this reason neutral fat has been estimated only when cholesterol esters were separately measured.

The normal standards used for the evaluation of data are those given in the first 2 papers of this series $(4,6)$.

\section{RESULTS}

\section{The concentration of lipids in the serum}

The concentrations of the 3 chief lipid fractions, cholesterol, lipid phosphorus and neutral fat, are shown in Figure 1, together with the diseases of the patients from which the sera were obtained. Certain rough correlations are at once evident.

Cholesterol is usually high in patients with obstructive jaundice, falling when the obstruction is relieved. This has been frequently noted before ( 7 to 11). The concentration of cholesterol continues to rise for some time after obstruction has been established, reaching extreme heights if obstruction persists for a considerable period. Examples of the course of the lipids in illustrative cases are presented in Figure 4. The degree of hypercholesterolemia in this and other series cannot, however, be correlated with the duration of the jaundice. This has led certain observers (8) to conclude that ultimately, if the obstruction is not relieved, cholesterol will again diminish, sometimes to subnormal concentrations. The features which determine the course of the hypercholesterolemia do not seem to be quite so simple as this. In this series, concentrations greater than
$400 \mathrm{mgm}$. per cent were seen within 4 to 12 days after the onset of obstruction; while values below $300 \mathrm{mgm}$. per cent were found from 4 to 9 weeks from the onset. In 1 case $862 \mathrm{mgm}$. per cent was found in a patient whose common duct had been presumably completely obstructed by a pancreatic carcinoma for 4 months. Concentrations below $300 \mathrm{mgm}$. per cent in the face of obstruction were observed under the following conditions: 1 . A patient with carcinoma of the ampulla of Vater developed jaundice with chills in November of 1942. His serum cholesterol, which was $243 \mathrm{mgm}$. per cent on May 28, 1943, rose during a series of operations for relief of the condition to $296 \mathrm{mgm}$. per cent on June 24, to fall off again when the obstruction had been relieved. He appears to have had remissions of jaundice during this long course. 2. In another case, values of 245 and 258 mgm. per cent were obtained from a patient with a metastatic carcinoma at a time when obstruction was probably incomplete; on the day of his death, 16 days later, when the icterus index had risen to 150 , his serum cholesterol was $530 \mathrm{mgm}$. per cent (see Figure 4, Case B36866). 3. A concentration of $222 \mathrm{mgm}$. per cent was found 3 days before death in a patient with primary carcinoma of the liver. The cholesterol was evidently falling since it had been $252 \mathrm{mgm}$. per cent a week earlier. 4. The serum cholesterol was only $207 \mathrm{mgm}$. per cent in a woman of 62 who had icterus for 3 months. The stools had been clay-colored until about a week before the determination of lipids. Although chemical tests for bile were reported negative in the hospital, the stools were described as brown or greenish. The icterus index also diminished. The obstruction had, therefore, probably been relieved. On Figure 1 appears a cholesterol of $485 \mathrm{mgm}$. per cent after operative relief of obstruction. In the 15 days after operation, this had fallen from $657 \mathrm{mgm}$. per cent (still earlier it had been $862 \mathrm{mgm}$. per cent). The patient did not remain long enough to permit further obobservations, but it may be presumed that the cholesterol continued to fall (see Figure 4, Case B49208). Biliary obstruction, therefore, causes cholesterol to rise strikingly and progressively. In the few instances in which hypercholesterolemia was not observed, obstruction appears to have been incomplete or else had been associated with 

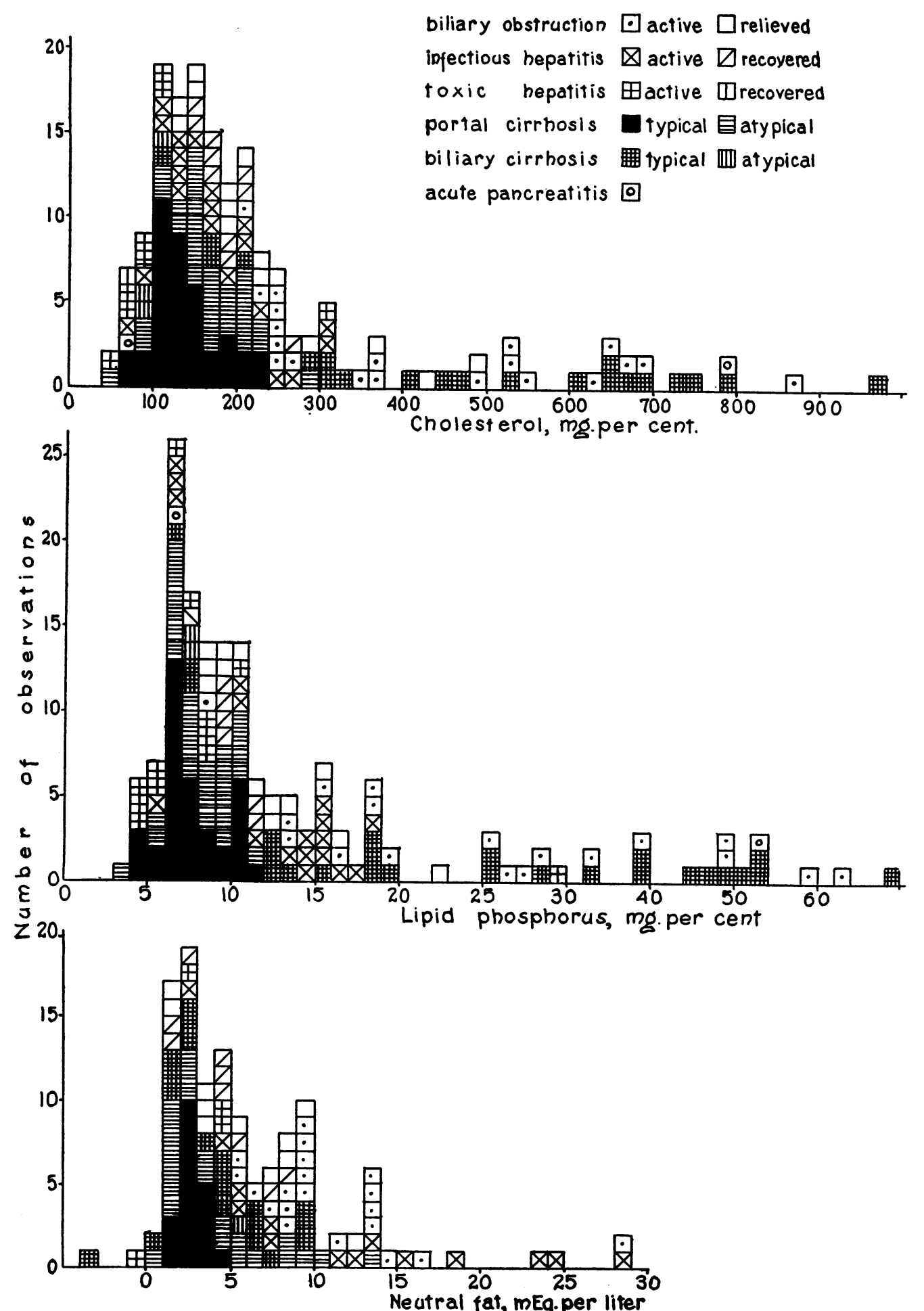

Fig. 1. Cholesterol, Lipid Phosphorus and Neutral Fat in the Serum of Patients with Vartous Types of Liver Disease 
extreme cachexia or with extensive destruction or degeneration of the parenchyma of the liver.

In general, cholesterol was higher in the patients with infectious hepatitis than it was in those with toxic hepatitis. There were, however, distinct exceptions to this rule. In 2 of the cases with infectious hepatitis, values below $100 \mathrm{mgm}$. per cent were observed. One of these accompanied an acute postpartum nephritis. True hypercholesterolemia, values greater than $300 \mathrm{mgm}$. per cent, was encountered only twice, in conjunction with acholic stools. It might have been noted more frequently if patients had been seen earlier in their illnesses. Illustrative cases are shown in Figure 5. In 3 cases with somewhat similar courses, studied only after icterus had begun to improve, cholesterols lay within normal limits. At least 1 of these had acholic stools earlier. Of the 8 patients with normal or high cholesterols, only
1 died; her icterus was a terminal feature accompanying pneumonia. Of the 7 with hypocholesterolemia (cholesterol less than $150 \mathrm{mgm}$. per cent), on the other hand, only 1 survived. It was noted that this patient had icterus when he was admitted to the hospital immediately after he had been scalded. How long the jaundice had persisted is as uncertain as its origin. As it subsided the serum cholesterol rose from 66 to $173 \mathrm{mgm}$. per cent. This is the only uncomplicated infectious case in which a cholesterol lower than $100 \mathrm{mgm}$. per cent was observed. On the other hand, concentrations below $100 \mathrm{mgm}$. were encountered in 4 patients in the terminal stages of hepatitis caused by drugs and chemicals. In these, jaundice was a late phenomenon overshadowed by symptoms of hepatic insufficiency. A diagnosis of arsphenamine hepatitis and encephalitis was made on a negress who, after antisyphilitic treatment, was admitted
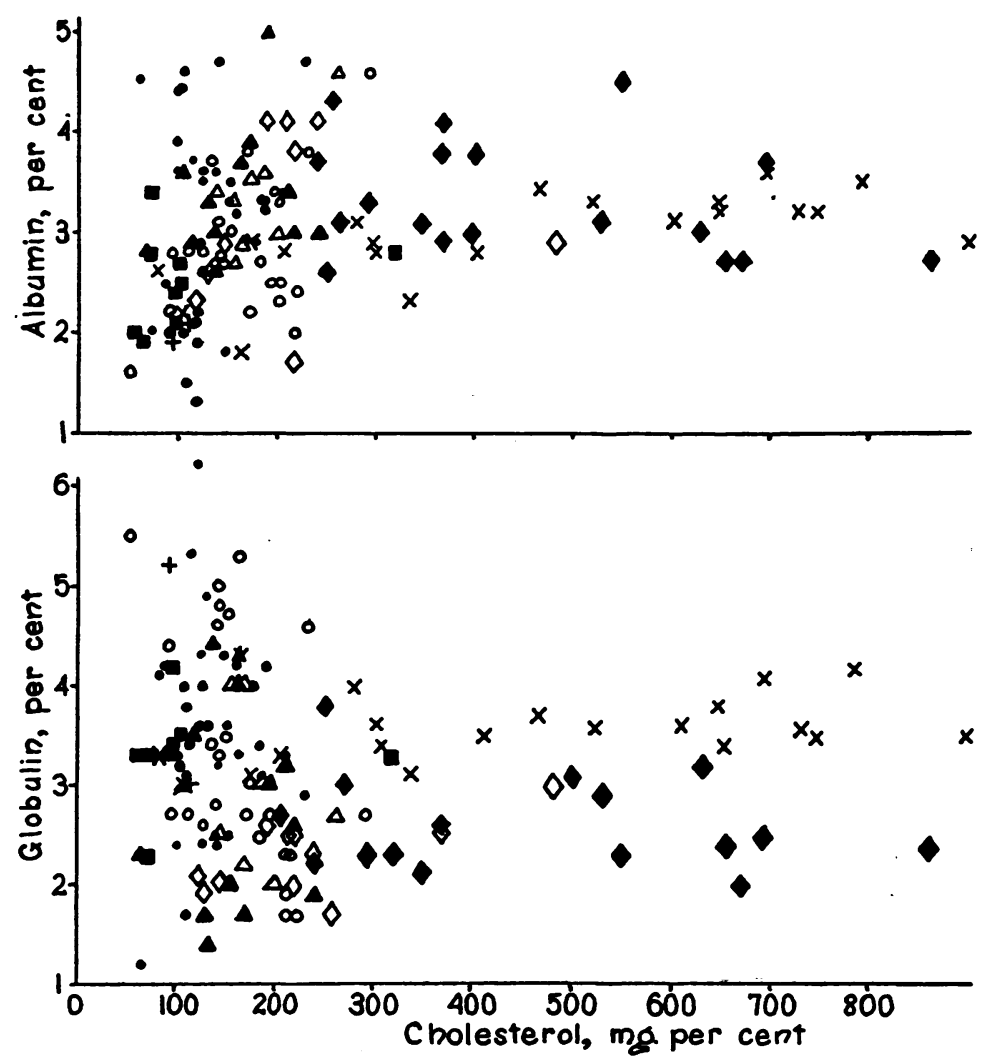

Biliary obstraction, active $\diamond$, relieved $\Delta$; infectioas bepatitis, active $\Delta$, recovered $\Delta$; toxic hepatitis, active $\square$, recovered $\square$; portal cirrhosis,typical•, atypical, 0; biliary cirrhosis, typical $x$, atypical + .

Fig. 2. The Relation of Cholesterol to Albumin and to Globulin in the Serum of Patients with Various Types of Liver Disease 
to the hospital with a temperature of $104.4^{\circ} \mathrm{F}$. in a semistuporous condition, with a number of anomalous features, including $x$-ray evidence of a tumor in the sella turcica. Serum cholesterol when she was improving was $318 \mathrm{mgm}$. per cent, the icterus index was 50. Despite a distortion of the interrelationships between the lipid fractions indicating a disorder of the liver, the cephalin flocculation test was negative. The diagnosis in this case, therefore, seems doubtful. The data on the whole suggest that hypercholesterolemia in hepatitis is an indication that the inflammatory condition has involved the bile ducts, causing obstruction. Whether this is a distinctive feature of certain types or stages of hepatitis is a suitable subject for inquiry.

In patients with typical portal cirrhosis, choles- terol was usually normal or low. In the cases with atypical portal cirrhosis, it lay in the same general range, although the average concentrations were somewhat higher. This difference depends largely on the inclusion in this group of certain cases. The patient with calcified adhesive pericarditis, despite intractable ascites, hepatomegaly and splenomegaly, had a normal serum lipid pattern throughout. This case accounts for 7 of the cholesterols above $160 \mathrm{mgm}$. per cent. Two others are contributed by another patient with heart failure. Three are from the patient who had dilated pancreatic ducts, and 1 from 1 of the patients with previous cholecystectomy. In 1 instance, the cholesterol rose from 129 to $179 \mathrm{mgm}$. per cent under therapy. Among the typical cases, 3 of the cholesterols above $160 \mathrm{mgm}$. per cent are from a pa-

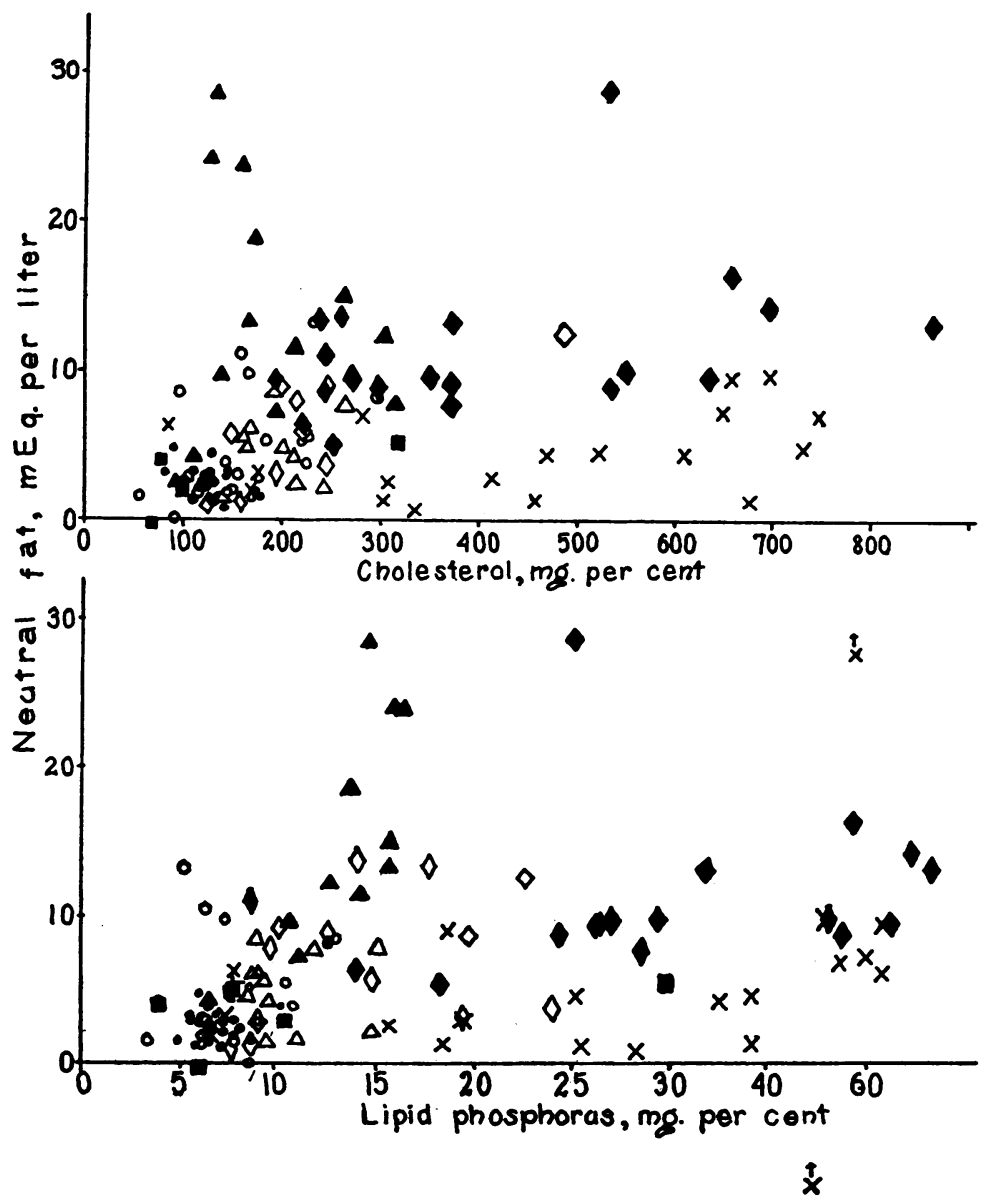

Fig. 3. The Relation of Neutral Fat to Cholesterol and to Lipid Phosphorus in the Serum of Patients with Various Types of Liver Disease

For interpretation of the symbols, see Figure 2. 
tient who had successive values of $189,185,161$, and $125 \mathrm{mgm}$. per cent. This probably illustrates the usual course of the disease. In 3 cases, however, the cholesterol rose in the course of the disease. In 1 instance a rise from 143 to $225 \mathrm{mgm}$. per cent marked a period of improvement in which ascites, previously requiring frequent paracentesis, was controlled by diet and diuretics. A rise from 154 to $208 \mathrm{mgm}$. per cent in another case attended symptomatic improvement. The third, when first seen, extremely malnourished, had a cholesterol of only $64 \mathrm{mgm}$. per cent. This rose to 112 and then to $229 \mathrm{mgm}$. per cent. Despite the fact that this woman died of a ruptured esophageal varix and suffered, besides, from heart failure, she never developed any considerable ascites. At autopsy, the liver was not characteristic of portal cirrhosis. Instead, there was a focal fibrosis, while the cells and architecture of most of the organ were well preserved.

The figures in biliary cirrhosis above $300 \mathrm{mgm}$. per cent are all from 1 patient who had also diabetes and necrobiosis (see Protocol 44700). Her course will be discussed in detail elsewhere. The patient with a cholesterol of $285 \mathrm{mgm}$. per cent also had a long-standing history of biliary stasis. Another patient with a similar condition had cholesterols of 167 and $177 \mathrm{mgm}$. per cent. It is known that cholesterol was 230 and $254 \mathrm{mgm}$. per cent $1 \frac{1}{2}$ years and 1 year earlier, respectively. Another with an acute history had a cholesterol of $207 \mathrm{mgm}$. per cent 2 weeks before death. The 2 cases with cholesterol below $150 \mathrm{mgm}$. per cent died after prolonged courses, in cachetic states, 1 with extreme recurrent ascites. The condition of the atypical cases can be judged from the sketches of their records given in the protocols. It may be inferred that recurrent or partial biliary obstruction gives rise to hypercholesterolemia which diminishes as hepatic destruction progresses, ultimately giving way to terminal hypocholesterolemia, either as a result of the extreme malnutrition or the loss of liver parenchyma.

In this connection, although serum proteins may seem irrelevant to a discussion of lipids, they may throw some light on the effect of malnutrition. It must be recognized, however, that they are criteria of nutrition in a special sense only. Much emphasis has been placed upon hyperglobulinemia in cirrhosis. In the present series (see Figure
2A), serum globulin was below 3 per cent 7 times in typical portal cirrhosis, 4 per cent or above 14 times, and 3 to 4 per cent 9 times. Corresponding figures for atypical cirrhosis were 10 below 3 per cent, 6 above 4 per cent, and 9 between 3 and 4 per cent. In addition, globulin exceeded 4 per cent 5 times in biliary cirrhosis, 3 times in active acute hepatitis, 3 times after recovery, and once in biliary obstruction. Hyperglobulinemia is not, therefore, a reliable diagnostic sign of portal cirrhosis. Serum albumin is reduced (less than 4 per cent) in most patients with liver disease (see Figure 2B). Although the lowest figures coincide with low cholesterol, there is no direct correlation between the 2 variables, nor is albumin consistently depressed in any particular disease. It is probably determined rather by the nutritive state of the patient.

Although attention in the past has been confined chiefly to cholesterol, phospholipid (12) is quite as much disturbed in diseases of the liver. In general, the 2 follow one another, rising and falling together. Figure 1 suggests that diseases are, perhaps, a little more sharply differentiated into categories by means of phospholipids than by cholesterol. The parallelism between phospholipids and cholesterol is well illustrated in Figures 4 and 5.

About the concentration of neutral fat in the serum, both in diseases and in experimental disorders of the liver, little can be found in the literature (12). Statements about this lipid component are based chiefly upon determinations of total lipids or total fatty acids. The latter are peculiarly unreliable measures of neutral fat in conditions in which, as in liver disease, the concentrations of phospholipids and cholesterol esters are greatly altered. From Figure 1, it appears that concentrations of neutral fat are not high in the serum of most patients with liver disease. In only 2 instances did neutral fat rise to the maximum encountered in normal subjects (4). Neutral fat is, however, high in biliary obstruction and in infectious hepatitis, as compared with cirrhosis and toxic hepatitis in which it is usually comparatively low. From Figures 4 and 5, it will be seen that in both biliary obstruction and in some cases of infectious hepatitis neutral fat rises, to fall again as the obstruction is relieved or the icterus subsides. Neutral fat is, of course, estimated on the 


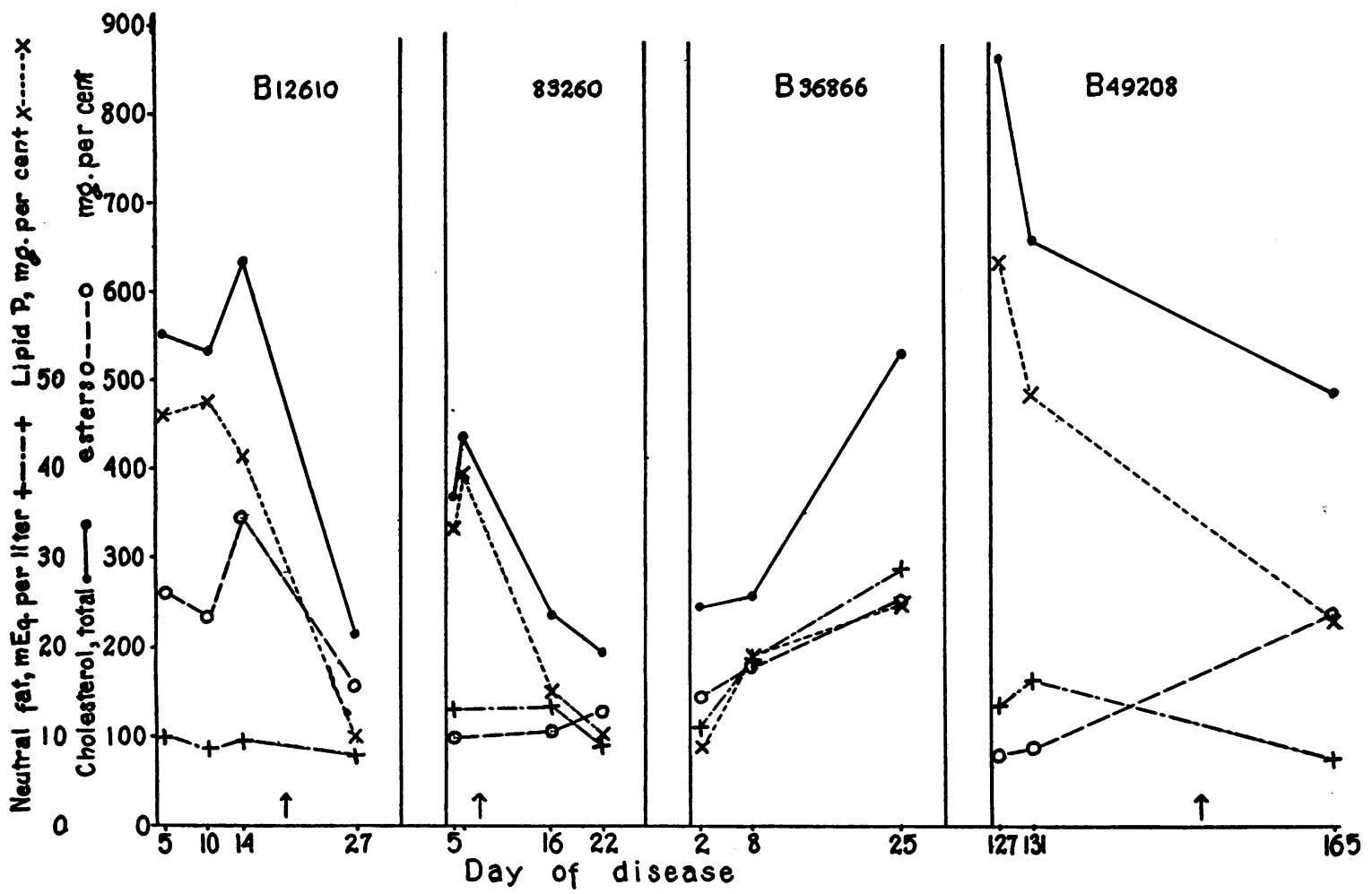

Fig. 4. The Course of the Serum Lipids in Patients with Biliary Obstruction For interpretation, see text.

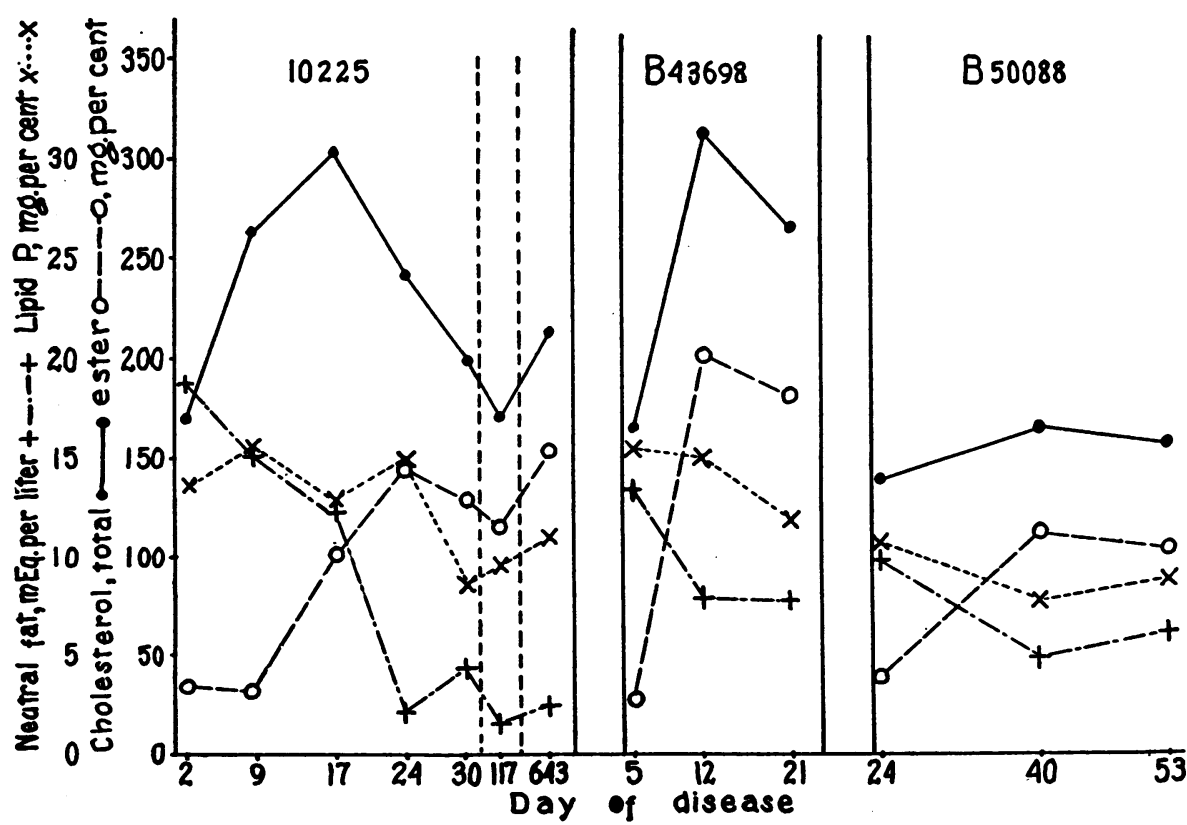

Fig. 5. The Course of the Serum Lipids in Patients with Infectious Hepatitis For interpretation, see text. 
assumption that the proportions of phospholipids remain constant. If, as lipid phosphorus rose, the increments consisted entirely of phospholipids with 2 fatty acids, while those with 1 fatty acid diminished, fatty acids could increase out of proportion to phosphorus without addition of neutral fat. Even if it were assumed that every phosphorus were combined with 2 equivalents of fatty acid, the neutral fat figures in this study would not be significantly altered. If, on the other hand, the phospholipids with only 1 fatty acid increased disproportionately, neutral fat would be much greater than Figure 1 indicates in patients with high lipid phosphorus.

Some idea of the effect this would have can be gained from Figure 3 in which neutral fat is compared with lipid phosphorus and cholesterol. There is a general tendency for all 3 fractions to vary together, but the correlation is not consistent. The most striking exception is the patient (44700) with chronic biliary tract disease, diabetes, and necrobiosis who is responsible for all the diagonal crosses above $300 \mathrm{mgm}$. per cent of cholesterol and $15 \mathrm{mgm}$. per cent of lipid phosphorus. There is reason to believe that neutral fat in this case was underestimated, since on 1 occasion calculation yielded a value of -8.5 m.eq. per liter of fatty acid. The general tenor of the data would not be altered if the neutral fat figures of this patient and those with obstructive jaundice were raised. It would still remain true that elevation of neutral fat is confined almost entirely to patients with obstructive jaundice and infectious hepatitis. Among the latter it is those with early intense jaundice that are chiefly affected. The highest figures of all, however, were observed in the patient with postabortional $E$. coli septicemia. From Figures 1, 3, 4 and 5 it can be seen that neutral fat rose proportionally more in hepatitis than it did in obstructive jaundice. The only case of cirrhosis with neutral fat greater than $10 \mathrm{~m}$.eq. per liter was the patient who had atypical portal cirrhosis with dilated pancreatic ducts.

\section{The interrelationships of the serum lipids}

It has been reported repeatedly that the ratio of free to total cholesterol is frequently elevated in hepatic disease $(8,9)$. Published data have, however, been obtained almost entirely by colorimetric procedures that yield higher and more variable ratios than does the digitonin method employed for the present study. For example, one worker (8) gave as the normal range of the cholesterol ratio 0.30 to 0.50 . On the other hand, in a large series of normal subjects several workers (13 to 15 , 4) found by digitonin methods that the ratio, free cholesterol : total cholesterol, never departed from the narrow limits of 0.24 to 0.32 . Furthermore, this relation was not disturbed in diseases of the thyroid gland (6), nephritis (16), and a variety of other disorders, in spite of the fact that these conditions greatly affected the concentration of cholesterol.

In Figure 6, total cholesterol and cholesterol esters of the patients of our series are compared. In only a few of the patients with cirrhosis is the ratio of esters to total cholesterol normal; in the others, it is invariably low. The grouping of points on the chart indicates that the distortion arises largely from a deficiency of ester forms. In only a few instances, when total cholesterol is greatly increased, does the concentration of esters exceed the upper normal limits; sometimes esters are almost extinguished. In patients with biliary obstruction and extreme hypercholesterolemia both fractions are sometimes elevated. In this condition and in acute hepatitis and biliary cirrhosis, the ratios are particularly reduced. From Figures 4 and 5 , it can be seen that cholesterol esters fall at the onset of obstruction or acute hepatitis, even before total cholesterol rises. Conversely, during recovery, esters rise and the ratio is restored before the total cholesterol falls. This is particularly evident in B49208, Figure 4. Before operation, ester cholesterol was only 80 and $85 \mathrm{mgm}$. per cent, with total cholesterol of 782 and 572 mgm. per cent. Normally, with cholesterol esters as low as this, total cholesterol could not exceed 118 and $125 \mathrm{mgm}$. per cent. Fifteen days after operation, with relief of the obstruction, the esters had risen to $236 \mathrm{mgm}$. per cent when the total cholesterol had fallen to only $485 \mathrm{mgm}$. per cent. It is this tendency for the ratio to approach normal before the concentration does that accounts for the obstruction and hyperlipemic acute hepatitis cases that have normal ratios in Figure 6.

In those patients who develop hypercholesterolemia, free cholesterol rises strikingly at the onset, as esters diminish. At the height of the hyper- 


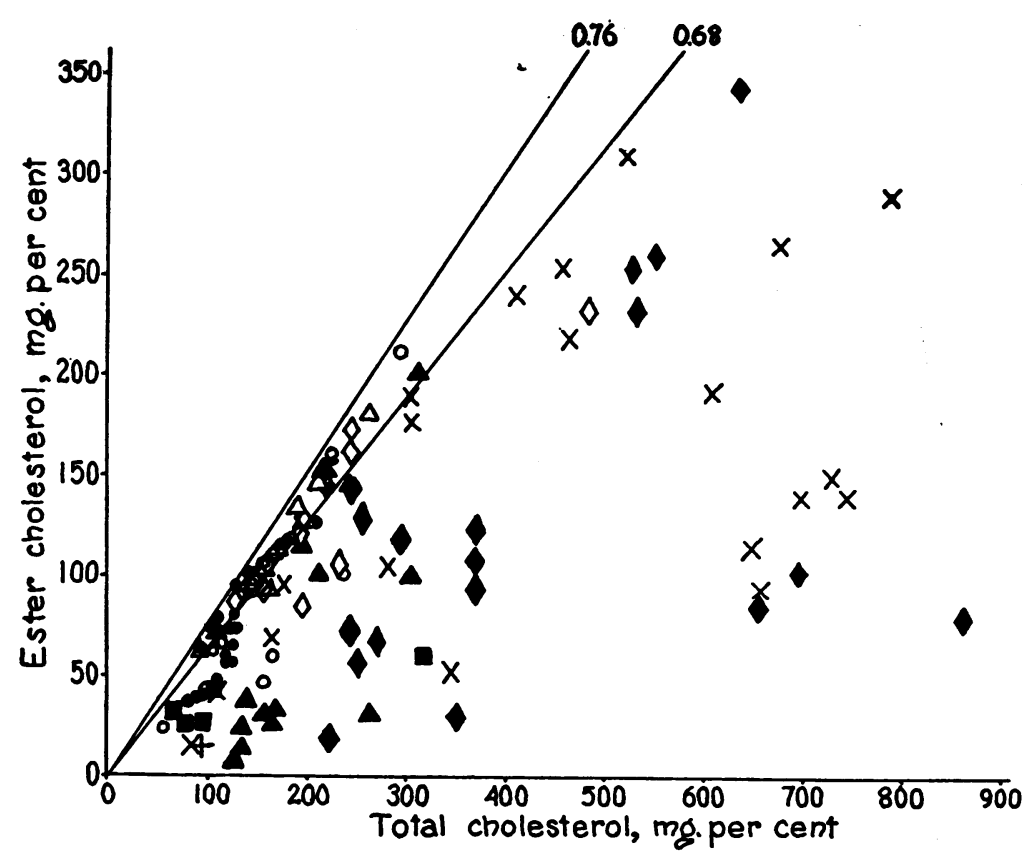

Fig. 6. The Relation of Cholesterol Esters to Total Cholesterol in Patients with Liver Disease

The diagonal lines defining ratios of 0.76 to 0.68 bound the zone of normal variation. For interpretation of the symbols, see Figure 2.

Solid circles $=$ typical, open circles $=$ atypical portal cirrhosis. Diagonal crosses $=$ typical, vertical crosses $=$ atypical biliary cirrhosis. Solid triangles $=$ active, open triangles $=$ recovered infectious hepatitis. Solid squares $=$ active, open squares $=$ recovered toxic hepatitis. Solid diamonds $=$ active, open diamonds $=$ relieved biliary obstruction.

lipemia, free cholesterol, which is normally a small fraction of the total, may exceed the normal value for total cholesterol. In 1 instance, of a total of $730 \mathrm{mgm}$. per cent, $530 \mathrm{mgm}$. per cent was in the free form. In patients with extreme hypocholesterolemia, on the other hand, free cholesterol, though high in proportion to the esters, may lie below the normal limits.

Just as the ratio of free cholesterol to total cholesterol is more constant than the concentration of total cholesterol or either of its fractions in the serum of normal persons, so the proportion of phospholipid to cholesterol is less variable than is the concentration of either phospholipid or cholesterol (6). The ratio, cholesterol:lipid phosphorus, however, is not constant, as is the ratio of free to total cholesterol, but increases with the cholesterol in a manner that has been described in an earlier paper (6).

In liver disease, lipid phosphorus, in general, parallels total cholesterol. The normal relations between the 2 are not, however, preserved. In most cases, the ratio of cholesterol to lipid phosphorus is lower than normal. Especially in the hyperlipemic cases, this distortion implies that phospholipids rise proportionally more than total cholesterol. In a review of the normal relation between these 2 lipid fractions, it was discovered that when lipid phosphorus is plotted directly against cholesterol, the distribution of points above $100 \mathrm{mgm}$. per cent of cholesterol is indistinguishable from a straight line. The distribution of points in thyroid diseases coincides with the distribution in normal persons or a rectilinear extension of this distribution. The best straight line calculated from 856 observations in which cholesterol varied from 108 to $911 \mathrm{mgm}$. per cent, was defined by the equation:

lipid phosphorus $=0.0294$ cholesterol +3.62 ,

$$
\text { S.D. }= \pm 1.043 \mathrm{mgm} \text {. per cent }
$$

This line meets the $y$ axis at a point indicating that 
cholesterol should disappear when the lipid phosphorus falls to $3.62 \mathrm{mgm}$. per cent. Actually cholesterol does not disappear, but falls at a slower rate than lipid phosphorus when the latter approaches this concentration. The curvilinear relation of the ratio, cholesterol:lipid phosphorus, to cholesterol, defined in an earlier paper (6) arises from the fact that the line defining the relations of these 2 fractions does not pass through the origin. By means of the linear relation defined by the new equation, it is possible to construct a graph somewhat like that used for the evaluation of the cholesterol ratio. This has been done in Figure 7. The radial lines define ratios of lipid phosphorus -3.62 to total cholesterol. The lines defining the normal limits, with slopes of 0.0205 and 0.0383 respectively have not as precise significance as those defining the limits of the cholesterol ratio, because the latter is more constant than the ratio of lipid phosphorus to cholesterol. These lines are drawn to include twice the mean deviation of the ratio at $200 \mathrm{mgm}$. per cent of cholesterol, which is about \pm 0.009 . The deviations are smaller at low than at high concentrations of cholesterol, which justifies, to some extent, the use of radial lines.

It is evident from Figure 7 that the ratio, lipid phosphorus:cholesterol, is unmistakably larger than normal in a large proportion of patients with liver disease. The most striking elevations are found in subjects with biliary obstruction and acute hepatitis. Certain exceptions are to be found. Among these are patients on the road to recovery from obstruction or hepatitis. This ratio, like the cholesterol ratio, seems to return to normal more rapidly than the concentrations of lipids do. Other exceptions are subjects with cholesterol below $100 \mathrm{mgm}$. per cent. To these, for reasons given above, the chart does not properly apply. The cirrhosis cases, for the most part, have normal ratios.

In Figure 8 , the ratio of free to total cholesterol is compared with that of lipid phosphorus to cholesterol. The horizontal and vertical lines define the normal limits of the 2 ratios. Area 5, therefore, presents the normal zone. In this area, lie patients who have recovered from acute hepatitis or have been relieved of biliary obstruction and a few cases of typical or atypical cirrhosis. There are no points in Areas 1, 4, and 7 which represent cholesterol ratios less than 0.24. Area 2 is also clear. This means that the ratio of lipid phosphorus to cholesterol is not altered if the cholesterol ratio is normal. Biliary obstruction and acute hepatitis tend to congregate in Area 3,

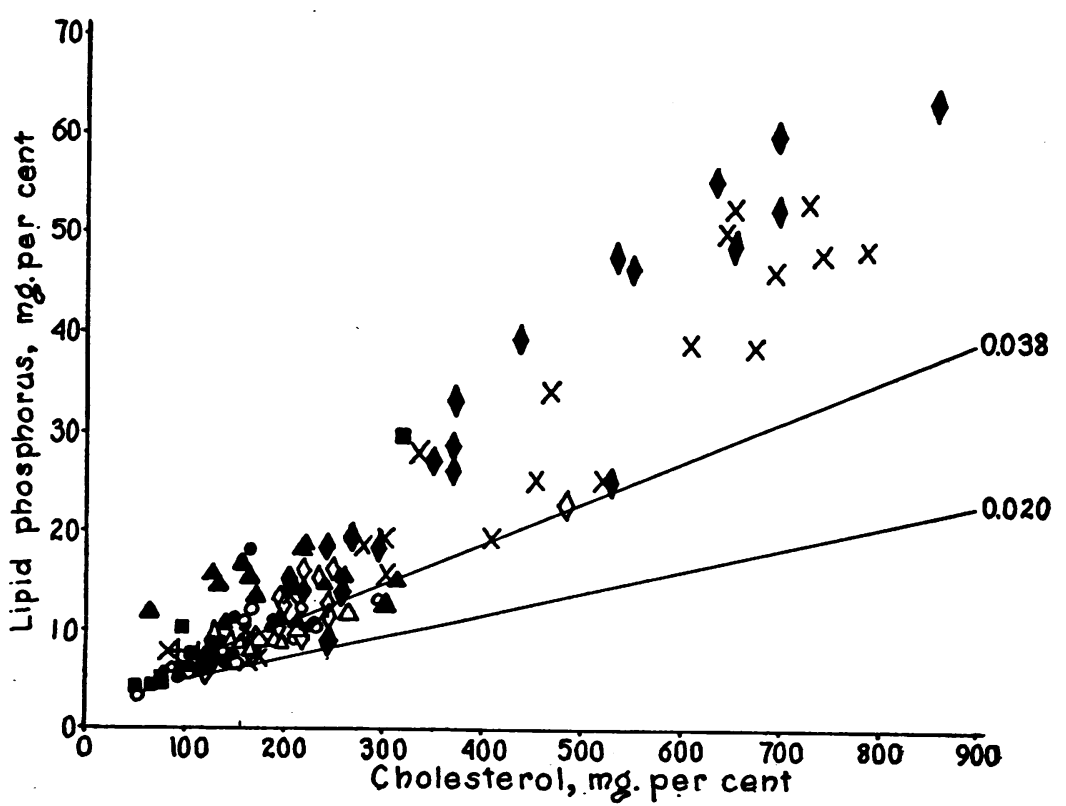

Fig. 7. The Relation of Lipid Phosphorus to Cholesterol

The diagonal lines bound the zone of normal variation of the ratio of lipid phosphorus-3.62 to cholesterol. For interpretation of the symbols, see Figure 6. 


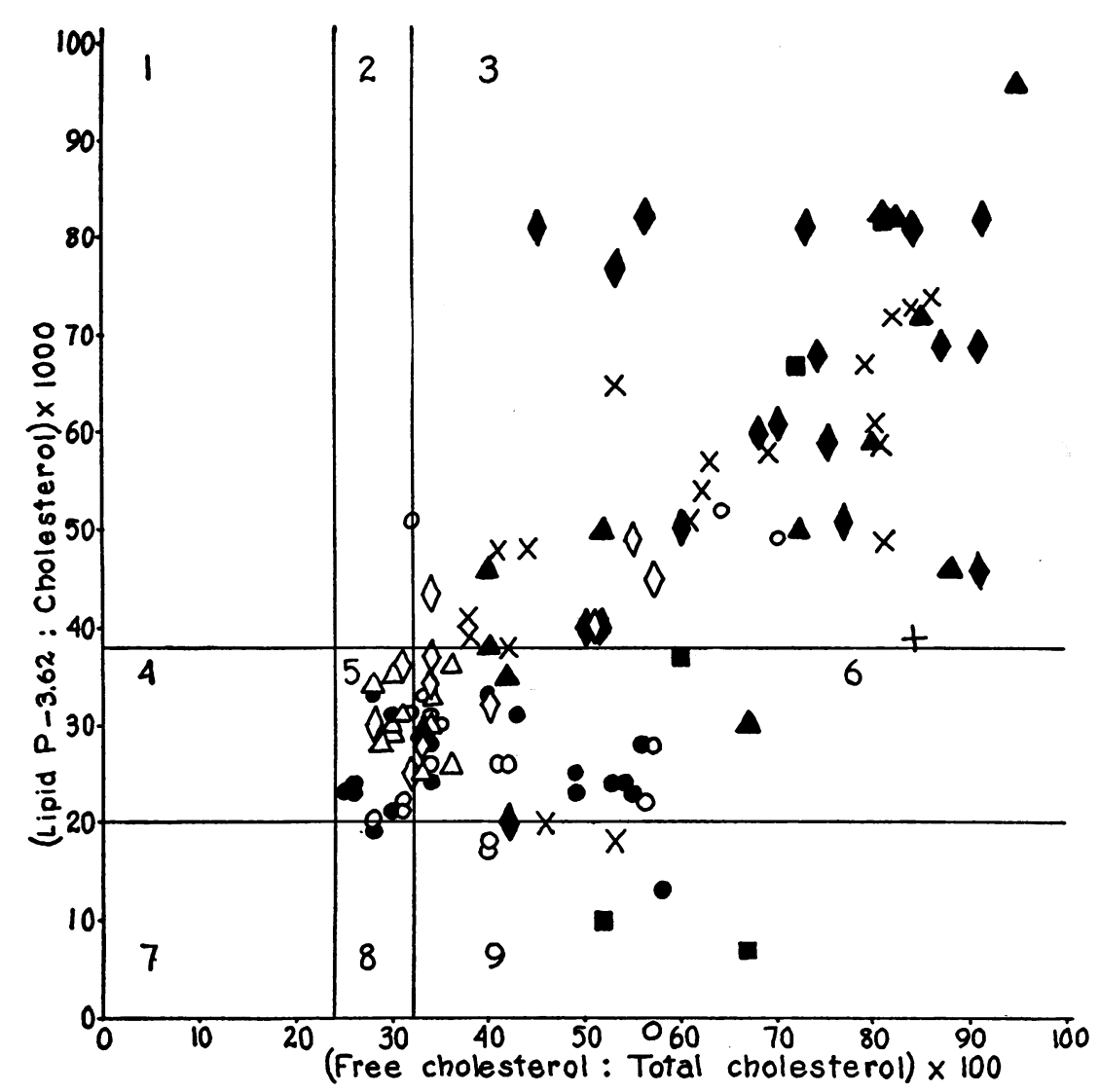

Fig. 8. The Relation of the Lipid Phosphorus: Cholesterol Ratio to the Cholesterol Ratio in Patients with Liver Disease

The vertical and horizontal parallel lines define the normal limits of variation to these ratios. For interpretation of the symbols, see Figure 6.

where both ratios are high. In this same area appear some subjects with atypical cirrhosis. As acute hepatitis and obstruction improve they frequently move through Area 6; that is, the lipid phosphorus:cholesterol ratio is restored earlier than the cholesterol ratio. In this area are also found most of the observations on typical and atypical cirrhosis. The few points in Areas 8 and 9 are almost all derived from patients with extreme hypolipemia.

\section{Lipotropic agents}

Choline chloride, in doses varying from 10 to 25 grams a day, was given for varying periods to 3 patients presumably suffering from portal cirrhosis. In none of them did it have any demonstrable effect upon the clinical course nor upon the serum lipids. Two of these subjects developed diarrhea when they took choline. This reaction occurred in 4 of the 8 patients who received this compound, but in 3 the diarrhea was transitory. The compound was also given to 3 patients with acute hepatitis. All three recovered, but it is impossible to say that their clinical courses were influenced by the choline. Another patient (Tables I and II, 28639) was given 10 grams subcutaneously on the second and third days preceding her death.

The course of the lipids in the eighth patient who received choline is illustrated in Figure 9 This is the patient with diabetes, necrobiosis, and chronic icterus with partial biliary obstruction and cholangitis (Protocol 44700). The serum lipids were greatly increased throughout her course, with strikingly high ratios of free to total cholesterol and of lipid phosphorus to cholesterol. The lipid picture resembled that of obstructive jaundice, with the exception that neutral fat was 
not elevated. Nevertheless, biliary obstruction was never complete. From the 96 th to the 113th day in the hospital, she was given 1 gram of choline chloride daily. Under this treatment cholesterol and lipid phosphorus fell and continued to decline in the next 2 weeks without choline. At the same time, the lipid ratios fell towards normal. Choline was again resumed on the 128 th day and was taken irregularly until the 167 th day. On the 186 th day, the serum lipids were almost normal. Subsequently they rose again, falling only shortly before death. No apparent improvement in the clinical condition accompanied the reduction of the serum lipids. Whether the latter can be attributed to the choline, it is impossible to state.

One of the patients with portal cirrhosis who had reacted to choline with diarrhea was given 3 grams of methionine daily for a month without any demonstrable change of clinical signs and symptoms or of serum lipids. Another patient who developed nephritis and hepatis enlargement with icterus during the puerperium, following erysipelas, was given 5 grams of methionine daily for 4 days shortly before death.

Lipocaic was given to a patient who developed fatty diarrhea and multiple vitamin deficiencies after a subtotal pancreatectomy for pancreatic carcinoma that had completely obstructed the common bile duct. Although she took as large doses of the material as she was able (up to 12 capsules a day), together with pancreatin and vitamins, she went rapidly and uninterruptedly downhill until her death. During her postoperative course, her lipids, which had been depressed, rose to the normal range despite extreme wasting. The lipid ratios, however, remained abnormal throughout.

\section{Liver analyses}

Results of the liver analyses are shown in Table I. For comparison in the same table are analyses of livers from 3 patients presumably free from hepatic disease and other disorders known to affect serum lipids, and a summary of similar analyses published by Ralli (17). The milliequivalents

TABLE I

Lipids of the liver

\begin{tabular}{|c|c|c|c|c|c|c|c|c|c|c|}
\hline \multirow{2}{*}{ Case number } & \multirow{2}{*}{$\begin{array}{l}\text { Hours af- } \\
\text { ter death }\end{array}$} & \multirow{2}{*}{$\begin{array}{c}\text { Liver } \\
\text { weight }\end{array}$} & \multirow{2}{*}{ Solids } & \multirow{2}{*}{$\begin{array}{c}\text { Fatty* } \\
\text { acids }\end{array}$} & \multirow{2}{*}{$\underset{\text { phosphorus }}{\text { Lipid }}$} & \multicolumn{4}{|c|}{ Cholesterol } & \multirow{2}{*}{$\underset{\text { fat }}{\text { Neutral }}$} \\
\hline & & & & & & Total & Free & Ester & Free:Ester & \\
\hline & & grams & $\begin{array}{c}\text { grams per } \\
\mathrm{kgm} .\end{array}$ & $\begin{array}{c}\text { meq. per } \\
\text { kgm. }\end{array}$ & $\begin{array}{c}\text { grams per } \\
\mathrm{kgm} .\end{array}$ & $\begin{array}{c}\text { grams per } \\
\mathrm{kgm} .\end{array}$ & $\begin{array}{c}\text { grams per } \\
\text { kgm. }\end{array}$ & $\begin{array}{c}\text { grams per } \\
\text { kgm. }\end{array}$ & & $\begin{array}{c}\text { m.eq. per } \\
\text { kgm. }\end{array}$ \\
\hline
\end{tabular}

Liver disease

\begin{tabular}{|c|c|c|c|c|c|c|c|c|c|c|}
\hline $\begin{array}{r}\text { B43797 } \\
\text { B36812 } \\
28639 \\
\text { A57138 } \\
19694 \\
\text { A47621 } \\
\text { B43658 } \\
\text { A45460 } \\
\text { B43742 }\end{array}$ & $\begin{array}{r}5.5 \\
16.0 \\
12.5 \\
22.5 \\
21.0 \\
16.0 \\
6.5 \\
7.5 \\
16.5\end{array}$ & $\begin{array}{r}4675 \\
2325 \\
2300 \\
650 \\
1525 \\
1050 \\
850\end{array}$ & $\begin{array}{l}319 \\
535 \\
197 \\
532 \\
228 \\
225 \\
197 \\
228 \\
184\end{array}$ & $\begin{array}{r}532.0 \\
1327.0 \\
63.9 \\
1036.5 \\
53.0 \\
190.6 \\
55.0 \\
95.8 \\
61.4\end{array}$ & $\begin{array}{l}0.963 \\
0.729 \\
1.207 \\
0.642 \\
0.832 \\
0.690 \\
0.803 \\
1.001 \\
0.713\end{array}$ & $\begin{array}{l}2.40 \\
2.05 \\
2.63 \\
6.76 \\
2.77 \\
3.09 \\
2.64 \\
3.49 \\
3.03\end{array}$ & $\begin{array}{l}1.27 \\
1.43 \\
2.51 \\
2.96 \\
2.80 \\
2.57 \\
2.05 \\
2.79 \\
2.70\end{array}$ & $\begin{array}{l}1.13 \\
0.62 \\
0.12 \\
3.80 \\
0.00 \\
0.52 \\
0.59 \\
0.70 \\
0.33\end{array}$ & $\begin{array}{l}0.53 \\
0.70 \\
0.95 \\
0.44 \\
1.00 \\
0.83 \\
0.78 \\
0.80 \\
0.89\end{array}$ & $\begin{array}{r}473.2 \\
1283.1 \\
-6.5 \\
988.4 \\
4.7 \\
149.1 \\
6.9 \\
35.9 \\
19.1\end{array}$ \\
\hline \multicolumn{11}{|c|}{ Normal } \\
\hline $\begin{array}{l}6269 \\
6270 \\
6366\end{array}$ & $\begin{array}{r}19.0 \\
8.0 \\
14.0\end{array}$ & $\begin{array}{l}2045 \\
1650 \\
1450\end{array}$ & $\begin{array}{l}297 \\
274 \\
284\end{array}$ & $\begin{array}{l}219.9 \\
188.5 \\
183.7\end{array}$ & $\begin{array}{l}1.139 \\
1.180 \\
1.284\end{array}$ & $\begin{array}{l}3.40 \\
3.74 \\
2.97\end{array}$ & $\begin{array}{l}2.09 \\
2.59 \\
2.26\end{array}$ & $\begin{array}{l}1.31 \\
1.15 \\
0.71\end{array}$ & $\begin{array}{l}0.62 \\
0.69 \\
0.76\end{array}$ & $\begin{array}{l}150.3 \\
116.9 \\
107.1\end{array}$ \\
\hline \multicolumn{11}{|c|}{ Ralli's (17) normals } \\
\hline $\begin{array}{l}\text { Minimum } \\
\text { Maximum } \\
\text { Average }\end{array}$ & & & v & $\begin{array}{r}59.1 \\
264.0 \\
128.0\end{array}$ & $\begin{array}{l}0.560 \\
1.167 \\
0.800\end{array}$ & $\begin{array}{l}2.40 \\
3.88 \\
2.83\end{array}$ & $\begin{array}{l}1.97 \\
2.17 \\
2.04\end{array}$ & $\begin{array}{l}0.43 \\
1.71 \\
0.79\end{array}$ & $\begin{array}{l}0.82 \\
0.56 \\
0.72\end{array}$ & $\begin{array}{r}25.5 \\
191.8 \\
79.5\end{array}$ \\
\hline
\end{tabular}

* Concentrations of all lipid components are referred to weight of fresh tissue. $\quad \dagger$ In terms of fatty acid. 
TABLE II

Serum lipids of patients with liver analyses

\begin{tabular}{|c|c|c|c|c|c|c|c|c|c|c|}
\hline \multirow{2}{*}{$\begin{array}{c}\text { Case } \\
\text { number }\end{array}$} & \multirow{2}{*}{ Date } & \multicolumn{2}{|c|}{ Serum protein } & \multirow{2}{*}{$\begin{array}{l}\text { Fatty } \\
\text { acid }\end{array}$} & \multirow{2}{*}{$\begin{array}{c}\text { Lipid } \\
\text { phosphorus }\end{array}$} & \multicolumn{3}{|c|}{ Cholesterol } & \multirow{2}{*}{$\begin{array}{c}\text { Lipid } \\
\text { phosphorus } \\
-3.6 \text { chol- } \\
\text { esterol }\end{array}$} & \multirow{2}{*}{$\underset{\text { fatt* }}{\text { Neutral }}$} \\
\hline & & Total & Albumin & & & Total & Free & Free:Total & & \\
\hline & & per cent & per cent & $\begin{array}{l}\text { m.eq. per } \\
\text { liter }\end{array}$ & $\underset{\text { per cent }}{m g m .}$ & $\underset{\text { per cent }}{m g m .}$ & $\underset{\text { per cent }}{m g m .}$ & & & $\begin{array}{l}\text { m.eq. per } \\
\text { liter }\end{array}$ \\
\hline B43797 & $\begin{array}{l}\text { June } 21 \\
\text { July } 20\end{array}$ & $\begin{array}{l}5.15 \\
4.94\end{array}$ & $\begin{array}{l}3.08 \\
2.81\end{array}$ & $\begin{array}{r}26.2 \\
9.5\end{array}$ & $\begin{array}{r}27.3 \\
7.2\end{array}$ & $\begin{array}{l}350 \\
138\end{array}$ & $\begin{array}{r}320 \\
46\end{array}$ & $\begin{array}{l}0.91 \\
0.33\end{array}$ & $\begin{array}{l}0.049 \\
0.068\end{array}$ & $\begin{array}{l}9.6 \\
2.9\end{array}$ \\
\hline B36812 & 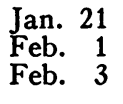 & $\begin{array}{l}8.19 \\
6.22\end{array}$ & $\begin{array}{l}2.93 \\
2.72\end{array}$ & $\begin{array}{l}18.4 \\
18.2 \\
21.8\end{array}$ & $\begin{array}{l}12.3 \\
11.1 \\
10.2\end{array}$ & $\begin{array}{l}166 \\
155 \\
234\end{array}$ & $\begin{array}{l}106 \\
108 \\
133\end{array}$ & $\begin{array}{l}0.64 \\
0.70 \\
0.57\end{array}$ & $\begin{array}{l}0.052 \\
0.049 \\
0.028\end{array}$ & $\begin{array}{r}9.7 \\
10.5 \\
13.3\end{array}$ \\
\hline 28639 & $\begin{array}{l}\text { May } 29 \\
\text { May } 30 \\
\text { May } 31 \\
\text { June } 1\end{array}$ & $\begin{array}{r}.5 .00 \\
4.64 \\
5.03\end{array}$ & $\begin{array}{l}3.30 \\
3.28 \\
3.01\end{array}$ & $\begin{array}{l}37.5 \\
36.2 \\
34.2 \\
33.6\end{array}$ & $\begin{array}{l}14.5 \\
16.7 \\
15.8\end{array}$ & $\begin{array}{l}132 \\
133 \\
157 \\
127\end{array}$ & $\begin{array}{l}108 \\
120 \\
127 \\
120\end{array}$ & $\begin{array}{l}0.82 \\
0.90 \\
0.81 \\
0.95\end{array}$ & $\begin{array}{l}0.082 \\
0.083 \\
0.096\end{array}$ & $\begin{array}{l}28.5 \\
23.7 \\
24.2\end{array}$ \\
\hline A57138 & $\begin{array}{c}1944 \\
\text { Nov. } 18\end{array}$ & 5.46 & 3.92 & 10.4 & 7.9 & 91 & 47 & 0.52 & 0.042 & 5.0 \\
\hline 19694 & $\begin{array}{l}1943 \\
\text { Mar. } 5\end{array}$ & 6.62 & 3.37 & 7.1 & 4.2 & 78 & 52 & 0.67 & 0.007 & 4.0 \\
\hline A47621 & $\begin{array}{l}\text { Jan. } 12 \\
\text { Jan. } 26\end{array}$ & $\begin{array}{l}6.14 \\
8.39\end{array}$ & $\begin{array}{l}2.03 \\
2.18\end{array}$ & $\begin{array}{l}6.5 \\
7.5\end{array}$ & $\begin{array}{l}5.6 \\
7.7\end{array}$ & $\begin{array}{r}79 \\
122\end{array}$ & $\begin{array}{l}42 \\
49\end{array}$ & $\begin{array}{l}0.53 \\
0.40\end{array}$ & $\begin{array}{l}0.024 \\
0.033\end{array}$ & $\begin{array}{l}3.2 \\
3.0\end{array}$ \\
\hline B43658 & June 4 & 5.85 & 2.91 & 6.1 & 5.5 & 104 & 42 & 0.40 & 0.018 & 2.9 \\
\hline A45460 & $\begin{array}{c}1944 \\
\text { Nov. } 14\end{array}$ & 6.25 & 1.77 & 7.4 & 6.1 & 139 & 63 & 0.45 & 0.018 & 1.9 \\
\hline B43742 & $\begin{array}{c}1943 \\
\text { Apr. } 3\end{array}$ & 7.08 & 1.90 & 10.3 & 7.7 & 93 & 78 & 0.84 & 0.044 & 5.4 \\
\hline
\end{tabular}

* In terms of fatty acid.

of fatty acid are calculated from this worker's figures, which are given in grams, by assuming that the fatty acids were composed of equal parts of stearic, oleic, and palmitic acids. The values for lipid phosphorus have been recalculated by means of the factor by which she converted lipid phosphorus to grams per cent of phospholipid (18). From these figures, neutral fat has been estimated by the formula used for the estimation of neutral fat from our own analyses. Her figures for neutral fat were not employed because they would not be comparable to ours. The results of analyses of sera from the patients whose livers were analyzed are shown in Table II. Abstracts of protocols of the cases are given at the end of the paper. The three "normal specimens" of liver were taken from the livers of: (1) a man of 50 years who committed suicide by taking cyanide, (2) a man of 31 years who died 6 hours after a coronary occlusion, (3) a man of 29 years who died from a stab wound of the heart.
Interpretation of analyses of tissues from human autopsy material presents several knotty problems. In the first place, it is not possible to secure the specimens in such a fresh state that autolytic changes can be excluded. Fortunately, lipids appear to be less subject to autolysis than carbohydrate and proteins are. Ralli (17) found that total cholesterol and fatty acids did not change, though lipid phosphorus decreased slightly in a dog's liver kept in the refrigerator for 23 hours. The differences in the "normal" analyses in Table I are not related to the interval between death and examination. It is difficult to obtain suitable normal control specimens. The 3 analyses in Table I are not sufficient to establish the range of normal variation. In composition, however, all three are relatively uniform. Ralli's (17) figures for all constituents are far more variable, and her series of analyses is far larger than ours. It may be that her material is more representative or that ours is more fortunately 
selected. In the general magnitude of all fractions, the two sets of analyses agree. Many others have reported liver analyses that differ widely from hers $(17,19)$ and ours, presumably because of the analytical techniques employed (20 to 23 ). It may be assumed that the structure of the livers of adults is relatively uniform, that the proportions of liver cells to connective tissue and other elements are approximately the same. It is quite otherwise in diseased livers. In cirrhosis, for example, the major part of a sample may consist, not of liver cells, but of undifferentiated connective tissue. The proportion of liver cells to connective tissue cannot be estimated, but it must have a great influence upon the chemical composition of the specimens taken for analysis.

There is no feature common to all the pathological livers; but the most frequent abnormality is a relatively low concentration of phospholipids. The first, second, and fourth cases are distinguished from all the others by the high proportions of solids they contain. This is associated with the presence of excessive quantities of fatty acids, of which an unusually large fraction belongs to neutral fats. In B43797 and B36812 pancreatic tissue was almost entirely destroyed, though neither had diabetes. These presumably are examples of true dietary fatty livers comparable to those that de-

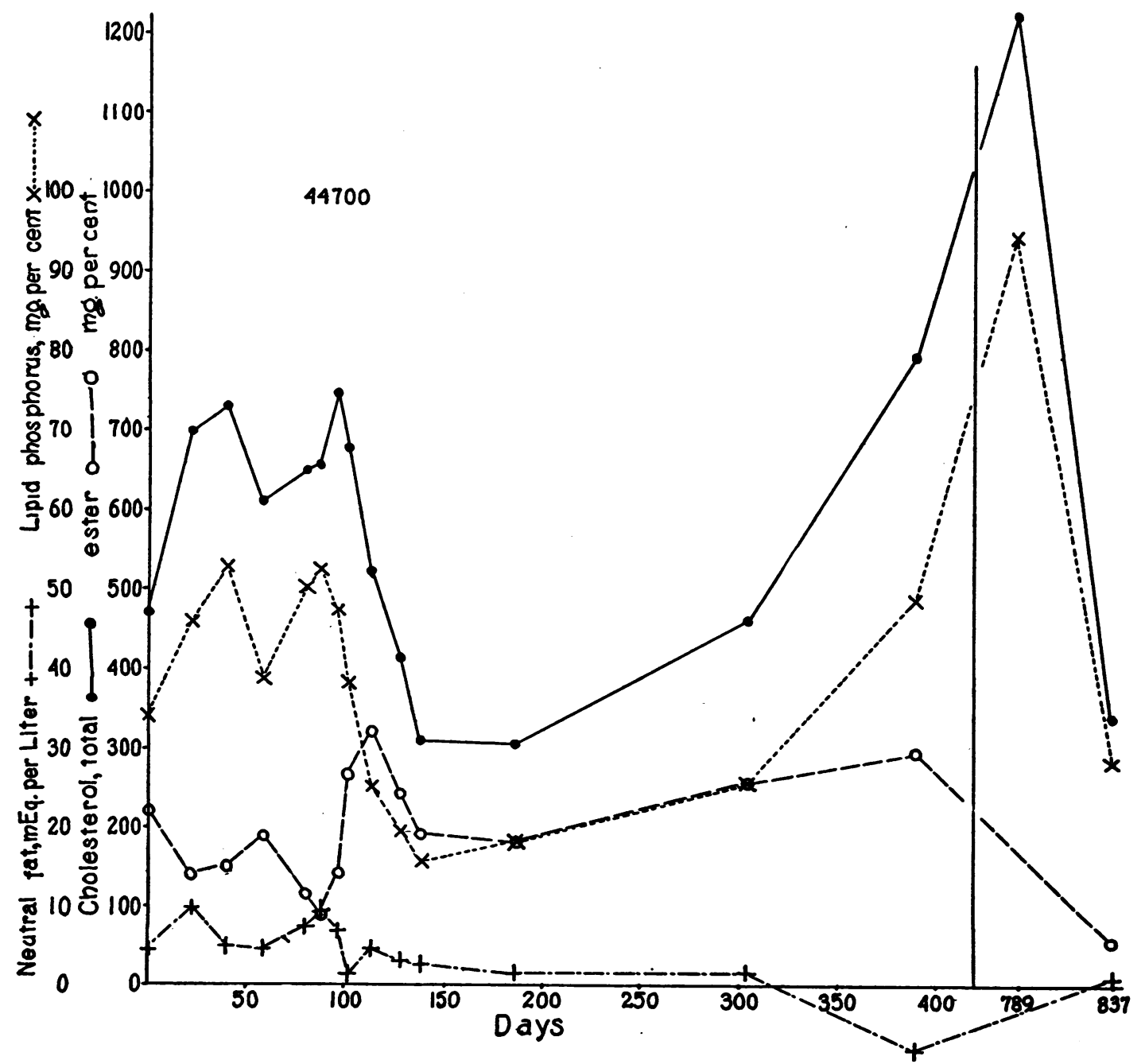

Fig. 9. The Course of the Serum Lipids of a Patient with Partial Biliary Obstruction, Cirrhosis, Diabetes and Necrobiosis and the Reaction of the Lipids to Choline 
velop in depancreatized animals treated with insulin. Phospholipids are reduced in both. Total cholesterol is also low, the deficiency affecting chiefly the free cholesterol fraction. B43797, when first observed, had high serum cholesterol, phospholipid, and moderately-elevated neutral fat in her serum, all of which fell before death, possibly because she had a biliary fistula. Cholesterol, lipid phosphorus, and neutral fat rose steadily in the serum of B36812, and the cholesterol ratio was high throughout. An erroneous diagnosis of portal cirrhosis was made because of an alcoholic history, a large liver, ascites, and high serum globulin. The serum lipid pattern, however, differs widely from that usually seen in portal cirrhosis, which is characterized by low concentrations of lipids and little distortion of the cholesterol ratio.

In some respects A57138 resembles the 2 preceding cases : total solids, fatty acids, and neutral fat are extremely high, lipid phosphorus greatly reduced, but cholesterol is enormously increased by accumulation of esters. This corresponds closely to the pattern of lipids described in the livers of animals with purely dietary fatty livers. Certainly from his history, the patient was entitled to such a condition. It is, however, impossible to evaluate or to discount the poisonous effects of the rubbing alcohol and the renal tubular destruction.

All the other livers of the series contain less than the normal complement of solids and in all but one, A47621, the deficiency can be attributed partly to a reduction of the concentration of fatty acids in the organ. Fatty infiltration in a gross sense is not, therefore, a consistent feature of hepatic disease. Case 28639 is peculiarly intriguing. Whether as a result of some unknown drug or puerperal sepsis, the patient had jaundice and other evidences of profound injury to the liver, is not known, and post mortem examination revealed no gross nor microscopic disturbance of hepatic structure. The chemical composition of the organ is profoundly altered, as might have been surmised from the serum analyses. The most striking change in both serum (last observation) and liver is the almost complete extinction of cholesterol esters and the relative preservation of the phospholipids. In fact, serum lipid phosphorus is high. This patient received choline for the last 3 days of her life. On the other hand, no neutral fat could be detected in the liver, although its concentration in the serum is extremely high, as if its utilization had been blocked. The calculation of neutral fat is, of course, subject to error because the composition of the phospholipids is unknown. If these contained an unusually large proportion of compounds containing only a single fatty acid, the neutral fat would be elevated somewhat.

The features common to this liver and that of 19694, who died of a toxic hepatitis, are the absence of cholesterol esters and the deficiency of neutral fat. Phospholipid is also low in 19694. All the lipid components in his serum were also reduced. These distinctions may arise from differences in the duration of the disease. Case 28639 died only a week after the onset of her illness, while 19694 had been exposed for months to the poison which killed him and had jaundice for at least 3 weeks before his death.

The 4 remaining patients died with cirrhosis of various degrees and kinds. The low solids and lipids cannot, therefore, be attributed altogether to changes in composition of the liver cells; replacement of these cells by connective tissue must be a contributory factor. The lipid constituents are not, however, uniformly affected. The concentrations of total cholesterol are quite well preserved. If the reductions of lipid phosphorus and fatty acids derive from replacement of liver cells by connective tissue, the liver cells must contain excessive amounts of cholesterol. Both morphologically and chemically the livers differed from one another. The most classical picture of portal cirrhosis was seen in B43658. With the exception of neutral fat, which is disproportionately low, the interrelationships of the lipid components in his liver are relatively well retained. The pattern of lipids in the liver of $\mathrm{A} 45460$ is very much the same, except for larger proportions of cholesterol and neutral fat. Both these patients had the characteristic hypolipemia of portal cirrhosis.

When allowance is made for the fibrous tissue in the liver of A47621, neutral fat and cholesterol appear to be elevated, while lipid phosphorus is depressed. Much central necrosis was found in this liver. The cholesterol ratio in both serum and liver was greatly elevated in B43742, whose liver showed a more diffuse fibrosis than the others with some evidence of bile-stasis. 


\section{DISCUSSION}

Although the amount of work involved in these analyses is large, the definite conclusions that can be drawn from them are comparatively meager. The material studied was so large and varied that no single condition was exhaustively examined. The investigation can be regarded only as a preliminary survey. The results are highly suggestive. They raise the hope that possibly such partitions of lipids may prove a more accurate means than the rather empirical tests thus far employed for the differentiation of hepatic disease and disorders. They may give more information than measurements of cholesterol and its fractions, to which attention has been largely confined. This is to be expected from experimental studies of dietary fatty livers and toxic hepatitis, in which it has been found that the formation of a balanced mixture of phospholipids is essential to the proper function of the liver and the orderly metabolism of fat (3).

Obstruction of the biliary passages appears to lead regularly to the accumulation in the serum of cholesterol, of phospholipids and, to a lesser extent, of neutral fat. The character of the cholesterol is also altered. Instead of consisting chiefly of esters, free forms predominate; esters are not only relatively, but absolutely, reduced. Available information indicates that cholesterol esters occur in the cells of only those organs or tissues in which there is active sterol metabolism: the liver, testes, adrenals, etc. This suggests that the metabolism of cholesterol is linked with the formation of esters. It has now been demonstrated that cholic acid is produced from cholesterol (24). In addition, large amounts of cholesterol are poured into the bile, chiefly in the free state. It is conceivable that obstruction to the escape of bile backs up these materials and retards the processes by which they are formed in the liver. This would explain the accumulation of free cholesterol in the serum and the reduction of esters. It has been demonstrated that administration of excessive amounts of cholesterol to rats is one of the most effective methods of producing fatty livers (25 to 29). The proportions of cholesterol esters in the livers of such rats are unusually large (25 to 29 ), while in the blood serum they are reduced $(30,31)$. The formation of phospholipids is dis- turbed, and the turnover of these compounds in the liver is retarded in this condition $(32,33)$. Cholesterol may compete with phospholipids for suitable fatty acids. Both cholesterol esters and phospholipids in proper proportions may be required for the orderly conduct of hepatic lipid metabolism. Whether all the phospholipid components of the serum are equally disturbed or whether the proportions of these components are altered by biliary obstruction remains to be determined. If the condition is similar in origin to the cholesterol fatty liver, it should respond to the administration of choline and other lipotropic factors (34). Some workers $(35,36)$ have, indeed, shown that in experimental biliary obstruction fatty infiltration of the liver can be minimized by the administration of high protein diets.

When the parenchyma of the liver is profoundly insulted by poisons or other destructive agents, the serum lipids appear to decrease. At the same time, the pattern of lipids is distorted in much the same manner as it is in biliary obstruction. This suggests that the maintenance of proper concentrations of lipids in the serum depends upon the presence of an adequate quantity of liver tissue, while the preservation of the normal pattern of lipids depends on the orderly function of the liver cells. This hypothesis would explain the fact that in cirrhosis concentrations of lipids are usually low, while patterns are little disturbed. Although the quantity of functioning liver tissue in cirrhoses is greatly reduced, the remaining cells may be comparatively normal. Distortions of patterns observed in particular cases would suggest that in these there is a more active process at work. It may be of some significance that such distortions were encountered more frequently in patients with atypical than they were in patients with typical cirrhosis.

In hepatitis 2 distinct types of disorders were seen. Certain cases had initial hyperlipemia, resembling in character, but seldom equalling in magnitude, that of obstructive icterus. Increases of cholesterol and lipid phosphorus were more moderate, while increases of neutral fat were greater in hepatitis. In other patients with infectious hepatitis and in the patients with toxic hepatitis, cholesterol and lipid phosphorus were low with an extreme, deficiency of cholesterol esters. Clinical evidence suggests that the hyper- 
lipemic cases had a greater degree of biliary obstruction than the others. If the hypotheses advanced above are sound, this should yield a hyperlipemia like that of biliary obstruction, but of smaller magnitude because of the injury to the liver cells. It is possible that the difference between the hyperlipemic and hypolipemic cases may depend upon etiological factors; it may prove to have prognostic significance.

The experiments with lipotropic agents offer little encouragement to the use of these agents, although they may have been of some benefit to 5 of the patients. This does not mean that these agents may not be useful therapeutic aids, but only that the cases or the dosage may have been improperly selected. There is experimental evidence that choline or methionine may prevent or alleviate the hepatic lesions produced by certain liver poisons and diseases $(1,2,37)$. These and other lipotropic agents will preserve the lives of pancreatectomized animals $(38,39)$. They will prevent or eliminate fatty infiltrations that result from dietary deficiencies. It has been suggested that similar fatty infiltrations characterize diseases of the liver arising from other causes. The series of liver analyses is all too small to warrant any generalizations or attempts to correlate lipid patterns of serum and liver closely. Like the serum analyses, it suggests that such correlations may be found by further studies of a similar nature. The diversity of the disorders in both sera and livers may explain the inefficacy of choline and other lipotropic agents in the cases to which they were given in this study. The benefits that may accrue from adding chemical analyses to morphological techniques is especially evident in such cases as 28639. This is more feasible with respect to lipids than to other compounds, since the lipids appear to be comparatively stable. It should be particularly informative when applied to the liver because this organ plays such an important rôle in the metabolism of lipids.

\section{SUMMARY AND CONCLUSIONS}

The serum lipids have been fractionated on 174 occasions in 70 patients with diseases of the liver and bile ducts.

Total cholesterol and lipid phosphorus are elevated in the serum of patients with biliary ob- struction, returning to normal when the condition is relieved by operation. They are also high in a certain proportion of patients with biliary cirrhosis and with infectious hepatitis. The latter group is composed chiefly of subjects who have had intense jaundice at the onset of their illness, with acholic stools. This suggests that hyperlipemia is a product of biliary obstruction.

Cholesterol and lipid phosphorus are normal or subnormal in most patients with portal cirrhosis, tending to fall as the disease advances. In patients with toxic hepatitis and some with infectious hepatitis, these lipid components are also reduced. This suggests that hypolipemia arises from extensive degeneration or destruction of liver parenchyma.

Neutral fat in liver disease seldom rises above the upper normal limits. It is, however, usually above the average normal, and occasionally greatly elevated, in obstructive icterus and infectious hepatitis, falling when obstruction has been relieved or when the hepatitis subsides.

The most frequent disorder of serum lipids in liver diseases is an increase of the ratio of free to total cholesterol. Free cholesterol is usually not only relatively but absolutely increased, while there is usually a deficiency of esters.

The relation of phospholipids to cholesterol in normal subjects has been redefined. In liver disease, especially in those disorders attended by hyperlipemia, the ratio of lipid phosphorus to cholesterol is greater than normal.

The two ratios, free cholesterol : total cholesterol and lipid phosphorus: total cholesterol, are differently and somewhat characteristically altered in various diseases of the liver.

Choline chloride and other lipotropic agents were given to a small series of patients with diseases of the liver, without definitely beneficial effects.

The lipids of the sera of 9 patients have been compared with the lipids of samples of liver obtained at autopsy.

\section{PROTOCOLS}

44700 , in addition to her hepatic condition, had diabetes and necrobiotic lesions of the extremities. These began as purplish nodules, the centers of which became necrotic and later ulcerated. Cultures of the necrotic material before ulceration were sterile; biopsies of the ulcers revealed 
only chronic inflammation. On the legs, the ulcers became confluent and quite extensive. Two years before she came to the New Haven Hospital, she had a period of intermittent jaundice without abdominal pain. Her liver was considerably enlarged. She died after enterostomy for symptoms suggesting intestinal obstruction. Post mortem examination revealed chronic cholecystitis and both extra- and intrahepatic cholangitis, stones partially obstructing the common bile duct, adhesions and abscesses around the gall-bladder, and abscesses in the liver. During her course of $2 \frac{1}{2}$ years in the hospital, she had jaundice of variable intensity, usually slight. The diabetes was satisfactorily controlled.

B43797, female, born in 1875 . For 20 years before admission on June 14, 1943, she had suffered from attacks of right upper quadrant pain, distention and eructations, lasting 1 or 2 days. Three weeks before admission she had sharp pain in the same area, followed shortly by chills, fever, jaundice, light-colored stools, and dark urine. On admission the temperature was $103.4^{\circ} \mathrm{F}$, the liver considerably enlarged and tender with a mass below it suggesting the gall-bladder. At operation on June 21, a hard tumor of the pancreas was reported and a cholecystojejunostomy was performed. Because fever and symptoms did not subside, an external choledocho-duodenostomy was performed on July 20 . She died 4 days later with a biliary fistula. Autopsy revealed a carcinoma of the pancreas which had obstructed the common bile duct and invaded the liver. No normal pancreatic tissue except a few islands of Langerhans could be found.

B36812, female, born in 1914 . In 1941, she was admitted to another hospital because of excessive menstrual bleeding, fever, and icterus. January 19, 1943, she was admitted to the New Haven Hospital because of increasing weakness and insomnia, continued menorrhagia, with tingling and numbness of the extremities, obviously alcoholic. She confessed to drinking a pint of whiskey a day but contended that she had developed this habit only after the attack of jaundice mentioned above. Because of the alcoholism, a moderately-enlarged liver, ascites and telangiectases, a diagnosis of portal cirrhosis was made. The cephalin flocculation test was 4 plus, the prothrombin time normal, there was 28 per cent retention of bromsulfalein at the end of 30 minutes, and she was slightly icteric. She was readmitted March 25, in shock, almost exsanguinated from vaginal bleeding, and died before either diagnostic or therapeutic measures could be instituted. Post mortem examination revealed only the slightest fibrosis of the liver which was tremendous. The hepatic cells were profusely infiltrated with fat. The pancreas, except for some islands of Langerhans, was entirely replaced by fibrous tissue, the remnants of the ducts were dilated, and the main duct was occluded near its entrance into the duodenum, for no discoverable cause.

28639, female, born 1913. On May 25, 1943, the patient aborted after insertion of a catheter into the uterus. The abortion was followed by profuse hemorrhage. On May 27, she was admitted to the hospital in coma and shock, with a blood pressure of $50 / 30$. She was given two 500 ml. transfusions of whole blood and some sulfadiazine. Fifteen hours later, deep jaundice was noted. In spite of further transfusions and all other therapeutic measures, she did not respond, dying on June 2. She was given, among other things, 10 grams of choline parenterally on May 30 and May 31. The blood culture yielded a pure growth of $E$. coli. On May 29, the cephalin flocculation test was 3 plus and the icterus index 100. Notwithstanding these evidences of liver damage and the abnormal serum lipids, the liver post mortem appeared altogether normal both grossly and microscopically. Acute endometritis and pelvic cellulitis were discovered. It is suspected that the patient had used drugs as well as mechanical means to promote abortion.

A57138, male, born in 1889, had been heavily alcoholic since youth and had been seen in the hospital and emergency ward on various occasions in a state of acute alcoholism. His eating habits were extremely irregular, his diet poor; on one occasion he was suspected of vitamin deficiency. On November 8, 1944, he initiated an alcoholic spree by drinking a pint of rubbing alcohol on a bet. On November 14, he came to the Emergency ward of the New Haven Hospital, weak and tremulous, complaining of a headache and epistaxis. The latter had recurred at intervals for 2 days. On November 16 he was admitted to the hospital after vomiting blood. He had eaten little since the beginning of his drinking bout. He appeared seriously ill and dehydrated, his liver was slightly enlarged, and he had some tenderness in the calves. The next day he became deeply icteric. Vomiting and epistaxis continued at intervals and ecchymoses appeared at the sites of parenteral fluid injections. He lapsed into coma in the course of the day. From the time of admission until his death he passed no urine and only $120 \mathrm{ml}$. could be obtained by catheter. This contained albumin, casts, and leukocytes. He died November 18 after a convulsion, despite all therapeutic measures, including frequent parenteral administration of large amounts of fluid containing carbohydrate in adequate quantities. The cephalin flocculation test was strongly positive, the icterus index 100 , and bromsulfalein retention more than 50 per cent at the end of 30 minutes. The liver was grossly fatty, the pancreas normal, spleen not enlarged. There was extensive degeneration and necrosis of the epithelium of the convoluted tubules of the kidneys.

19694, male, born in 1913, was admitted to the New Haven Hospital on March 5, 1943. For about 8 months he had been exposed in his occupation to an organic halide preparation. He continued to work for a week after the appearance of jaundice, 3 weeks before admission, but was then forced to desist because of weakness and vomiting which increased steadily. On March 2, blood was noted in the vomitus, and on March 4 he became stuporous. On admission he was comatose, deeply jaundiced, and retching. There was a papular rash on his back. The icterus index was greater than 125 . He died within 24 hours. At autopsy, the liver was the site of profuse hemorrhages and extensive necrosis, with little evidence of regeneration. 
A47621, female, born in 1908, had been treated for syphilis from 1935 to 1937 . Both Kahn and Wassermann tests were negative. Enlargement of the liver and spleen were discovered when she was admitted to the hospital in 1939 because of alcoholism and lysol poisoning. She was readmitted in 1942 because of a fissure in ano, external hemorrhoids and a secondary anemia. The last probably arose from rectal bleeding together with malnutrition. The liver was again noted to be slightly enlarged. On January 4, 1943, she again entered the hospital with erysipelas of the left leg. This time she had slight ascites and subcutaneous edema. The lipid studies were made after the erysipelas had subsided. On April 29, she returned to the hospital in shock, almost exsanguinated from a ruptured esophageal varix, and died an hour later despite transfusion and infusions. Autopsy revealed a distinct portal cirrhosis with rather extensive acute necrosis in the central portions of the islands of liver tissue.

B43658, male, born in 1884, was first seen in the Dispensary on March 31, 1943, with a history of edema of the feet and legs for 2 to 3 weeks, with exertional dyspnea, unproductive cough, and scleral icterus, with light-colored stools for a week. He had an enlarged heart, ascites, a large liver, and marked edema of the legs. There was no alcoholic history. The icterus index was 20 . He was admitted to the New Haven Hospital May 29, somewhat stuporous, with edema up to his nipples. On May 31, his gums began to bleed, and on June 2 gross rectal bleeding was noted. The next day his temperature rose sharply to $104.6^{\circ} \mathrm{F}$. He died June 4. The icterus index was 35 , the cephalin flocculation test 2 plus. Autopsy revealed a classical picture of portal cirrhosis with enormous amounts of fibrous tissue and small islands of liver tissue in which the cells appeared relatively normal.

A45460, male, born in 1883, was in the habit of consuming 4 to 5 quarts of beer daily in addition to an occasional glass of whisky. In 1939, he was admitted to the New Haven Hospital because of nausea, vomiting, diarrhea, and jaundice. The liver was greatly enlarged, the icterus index 55. He ran a febrile course for 2 weeks, after which he gradually improved, the liver diminishing in size and jaundice receding. He was again admitted to the New Haven Hospital November 12, 1944, with ascites of 8 weeks' duration, productive cough, exertional dyspnea, and bleeding from the rectum. His abdomen was greatly distended with fluid. After removal of 10 liters, the liver could just be felt beneath the costal margin; the spleen was never palpable. Skin and sclerae were moderately icteric, the icterus index was 50 , and bromsulfalein retention 24 per cent at the end of 30 minutes. On November 15 , he suddenly vomited bright-red blood, his blood pressure fell progressively, and he lapsed into coma. He died later in the day. His blood sugar shortly before death was $46 \mathrm{mgm}$. per cent. Post mortem examination revealed an advanced portal cirrhosis of the liver in which the connective tissue and, to a lesser extent, the islands of parenchyma were densely infiltrated with mononuclear cells and with numerous polymorphonuclear leukocytes.

B43742, male, born in 1889 . In 1926, during a cholecystectomy, some generalized fibrosis of the liver was noted. In 1939 or 1940 , enlargement of the liver was reported. From November, 1942, he noticed increasing malaise, loss of weight, anorexia and flatulence. Early in March, 1943, after a coryza, he was seized with stabbing pain in the right axilla, accompanied by a cough, and a temperature of $101^{\circ} \mathrm{F}$. Five days later, jaundice appeared and increased steadily. Shortly after this, the stools became black from changed blood. He was admitted to another hospital, deeply jaundiced, with a large liver and fever. Because of anorexia, vomiting, and hiccough he was unable to eat and deteriorated rapidly. On March 3, he was transferred to the New Haven Hospital in a stuporous state, extremely emaciated, with tense ascites, and a huge liver. He died on March 6 . The icterus index was 60 , cephalin flocculation 3 plus, prothrombin time 120 seconds (normal control 12.8). Autopsy revealed diffuse fibrosis of the liver without large scars, some necrosis of the liver cells, some proliferation of the bile ducts, and moderate evidence of biliary stasis. Little sound liver tissue remained. In addition, there was carcinoma of the liver. The sample for analysis was taken from an area free from carcinoma.

\section{BIBLIOGRAPHY}

1. Barrett, H. M., Best, C. H., MacLean, D. L., and Ridout, J. H., The effect of choline on the fatty liver of carbon tetrachloride poisoning. J. Physiol., 1939, 97, 103.

2. Goodell, J. P. B., Hanson, P. C., and Hawkins, W. B., Methionine protects against mepharsen liver injury in protein-depleted dogs. J. Exper. Med., 1944, 79, 625.

3. McHenry, E. W., and Patterson, J. M., Lipotropic factors. Physiol. Rev., 1944, 24, 128.

4. Peters, J. P., and Man, E. B., The interrelations of serum lipids in normal persons. J. Clin. Invest., 1943, 22, 707.

5. Mann, F. C., Diet in relation to hepatic physiology and pathology. A review of pertinent data. Collected papers, Mayo Clinic and Mayo Foundation, 1943, 35, 34.

6. Peters, J. P., and Man, E. B., The interrelations of serum lipids in patients with thyroid disease. J. Clin. Invest., 1943, 22, 715.

7. Epstein, E. Z., Cholesterol of the blood plasma in hepatic and biliary diseases. Arch. Int. Med., 1932, 50, 203.

8. Epstein, E. Z., and Greenspan, E. B., Clinical significance of the cholesterol partition of the blood plasma in hepatic and in biliary diseases. Arch. Int. Med., 1936, 58, 860.

9. Gardner, J. A., and Gainsborough, H., Blood cholesterol studies in biliary and hepatic disease. Quart. J. Med., 1930, 23, 465.

10. Hawkins, W. B., and Wright, A., Blood plasma cholesterol: fluctuations due to liver injury and bile duct obstruction. J. Exper. Med., 1934, 59, 427. 
11. Heinlein, H., Die Rolle der Leber im Cholesterin- und Phosphatidstoffwechsel. Ztschr. f. d. ges. exper. Med., 1933, 91, 638.

12. Boyd, E. M., and Connell, W. F., Lipopenia associated with cholesterol Estersturz in parenchymatous hepatic disease. Arch. Int. Med., 1938, 61, 755.

13. Brun, G., Changes in the lipide contents of serum in patients with manic-depressive psychosis. H. K. Lewis, London, 1940.

14. Sperry, W. M., The concentration of total cholesterol in the blood serum. J. Biol. Chem., 1937, 117, 391.

15. Jones, C. A., A clinical and laboratory study of plasma lipids in obstructive jaundice and several types of hepatic disease. Am. J. Digest. Dis., 1942, 9, 1.

16. Peters, J. P., and Man, E. B., The interrelations of serum lipids in patients with diseases of the kidneys. J. Clin. Invest., 1943, 22, 721.

17. Ralli, E. P., Rubin, S. H., and Rinzler, S., The liver lipids in normal human livers and in cases of cirrhosis and fatty infiltration of the liver. J. Clin. Invest., 1941, 20, 93.

18. Rubin, S. H., Present, C. H., and Ralli, E. P., The liver lipids in normal dogs on different types of fat with and without added lecithin. J. Biol. Chem., 1937, 121, 19.

19. Ralli, E. P., Paley, K., and Rubin, S. H., The liver lipids and their distribution in disease. An analysis of 60 human livers. J. Clin. Invest., 1941, 20, 413.

20. Cowie, D. M., and Magee, M.C., Lipoids and lipoid diseases. III. Lipoid content of tissues in SchüllerChristian's disease (xanthomatosis) and review of literature on lipoid content of human tissues. Arch. Int. Med., 1934, 53, 391.

21. Thannhauser, S. J., and Reinstein, H., Fatty changes in the liver from different causes. Arch. Path., 1942, 33, 646.

22. Rourke, G. M., and Stewart, J. D., Composition of the liver. Its uniformity with respect to the concentration of certain biochemical constituents in different parts of the same liver. Arch. Path., 1942, 33, 603.

23. Fagin, I. D., Sahyun, M., and Pagel, R. W., Cirrhosis of the liver: the lipotropic action of parenterally administered amino acids. J. Lab. and Clin. Med., 1943, $28,987$.

24. Bloch, K., Berg, B. N., and Rittenberg, D., The biological conversion of cholesterol to cholic acid. J. Biol. Chem., 1943, 149, 511.

25. Best, C. H., Channon, H. J., and Ridout, J. H., Choline and the dietary production of fatty livers. J. Physiol., 1934, 81, 409.
26. Best, C. H., and Ridout, J. H., The effects of cholesterol and choline on deposition of liver fat. $\mathrm{J}$. Physiol., 1933, 78, 415.

27. Cook, R. P., Cholesterol feeding and fat metabolism. Biochem. J., 1936, 30, 1630.

28. Ralli, E. P., Rubin, S. H., and Present, C. H., The liver lipids and fecal excretion of fat and nitrogen in dogs with ligated pancreatic ducts. Am. J. Physiol., 1938, 122, 43.

29. Stetten, DeW., Jr., and Grail, G. F., Effect of dietary choline, ethanolamine, serine, cystine, homocysteine, and guanidoacetic acid on the liver lipids of rats. J. Biol. Chem., 1942, 144, 175.

30. Chaikoff, I. L., and Kaplan, A., The blood lipids in completely depancreatized dogs maintained with insulin. J. Biol. Chem., 1934, 106, 267.

31. Kaplan, A., and Chaikoff, I. L., The effect of raw and autoclaved pancreas on the liver lipids of the completely depancreatized dog maintained with insulin. J. Biol. Chem., 1937, 119, 435.

32. Perlman, I., and Chaikoff, I. L., Radioactive phosphorus as an indicator of phospholipid metabolism. V. On the mechanism of the action of choline upon the liver of the fat-fed rat. J. Biol. Chem., 1939, 127, 211.

33. VII. The influence of cholesterol upon phospholipid turnover in the liver. J. Biol. Chem., 1939, 128, 735.

34. Gavin, G., Patterson, J. M., and McHenry, E. W., Comparison of the lipotropic effects of choline, inositol, and lipocaic in rats. J. Biol. Chem., 1943, 148, 275.

35. Johnson, J., Ravdin, I. S., Vars, H. M., and Zintel, $H$.A., Effect of diet on composition of the liver in the presence of obstruction of the common bile duct. Arch. Surg., 1940, 40, 1104.

36. Ravdin, I. S., Thorogood, E., Riegel, C., Peters, R., and Rhoads, J. E., The prevention of liver damage and the facilitation of repair in the liver by diet. J. A. M. A., 1943, 121, 322.

37. Sellards, A. W., and McCann, W. S., Choline hydrochloride in experimental yellow fever in rhesus monkeys. U. S. Nav. M. Bull., 1944, 43, 420.

38. Entenman, C., and Chaikoff, I. L., Is choline the factor in the pancreas that prevents fatty livers in depancreatized dogs maintained with insulin? J. Biol. Chem., 1941, 138, 477.

39. Ralli, E. P., and Rubin, S. H., The effect of meat and meat fractions on the fatty liver of the depancreatized and pancreatic-duct-ligated dog. Am. J. Physiol., 1942, 138, 42. 